\title{
AN APPROACH TO EXTRACTING FAÇADE FEATURES USING THE INTENSITY VALUE OF TERRESTRIAL LASER SCANNER WITH MATHEMATICAL MORPHOLOGY
}

\author{
Alex Soria-Medina ${ }^{1}$, Joaquín Martínez ${ }^{2}$, Alzir Felippe Buffara-Antunes ${ }^{1}$, \\ Pedro Arias ${ }^{2}$, and Higinio González-Jorge ${ }^{2}$ \\ ${ }^{1}$ Geomatics Department, Federal University of Parana, Curitiba, Parana, Brazil \\ ${ }^{2}$ Natural Resources and Environmental Engineering Department, School of Mining Engineering, \\ University of Vigo, Rua Maxwell S/N, Vigo, Spain \\ *Corresponding author (asmedina@ufpr.br)
}

\begin{abstract}
Nowadays, Terrestrial Laser Scanner (TLS) is a crucial device in order to acquire geographical data easily. In recent years, advances in accuracy and velocity have enhanced 3D models, but these stand-alone data do not provide the feature extraction. High density point clouds can be obtained with terrestrial laser scanner and by means of modelling and processing techniques, objects features can be constructed. Generally researchers use the geometric information for extracting object characteristics. This paper describes a methodology to use not only the geometrical information but also the intensity data provided during the scan process. The aim of this paper is to present a methodology to extract façades from laser scanner data. The proposed method uses mathematical morphology to classify, segment and extract the borders of principal features of the building "Quiñones de León country mansion" in the city of Vigo, Galicia, Spain. Furthermore, the final result shows huge potential of the intensity data solution to extract the main features of façades and together with the K-means algorithm for segmentation and mathematical morphology operators. It suggests keeping the effort going on combining them as successful tools employed for feature extraction of historical buildings.
\end{abstract}

Keywords: Terrestrial Laser Scanner, Features Extraction, Mathematical Morphology, Intensity Value

\section{INTRODUCTION}

Research into the historical significance of what humans were and how they lived throughout time is reflected nowadays in landscapes and cultural life. Modern Day society is anxious to discover its own significance here through the identification, documentation, preservation and restoration of monuments and heritage collections.

Most surveys evaluating architectural documentation and heritage registers, whether for building demolitions, interventions or restorations, do not use terrestrial laser scanner in this documentation. The necessity of increasing knowledge about the terrestrial laser scanner becomes clear for professionals such as architects, engineers and restorers, because it is an important tool for obtaining fast and accurate data needed for the documentation and dissemination of patrimonial and architectural assets.

These days terrestrial laser scanner systems are being widely used to capture three-dimensional information of natural and man-made surfaces (buildings). The TLS system has shown promising applications in building reconstruction by extracting details of the façades [1], documentation of historic sites, architectural applications, geology[2], archaeology [3,4], geomorphologic analyses [5] as well as in industrial applications [6], mainly because it is a non-destructive, highly accurate technique, which makes it very attractive for carrying out this type of work.

Given the fact that laser scanning is a non-destructive technique, in recent years it has undergone a breakthrough with regard to the generation of metric and 
graphical documents, without any direct contact with the constructions in question. Terrestrial laser scanners are systems generating point clouds containing threedimensional coordinates $(\mathrm{X}, \mathrm{Y}, \mathrm{Z})$, an intensity value and RGB (Red, Green, Blue) information from any surface or object.

In this sense, the information extraction from the point cloud is an extremely important step and this procedure could be manual, semi-automatic or automatic.

Several algorithms have been proposed to this effect, using this positional information contained in the laser scanner data, allowing the extraction of planar surfaces and correlating this information with building features. According to Pu et al.[1], this is an important and crucial step in the recognition of features and will give accuracy in subsequent steps. Moreover, the information provided by the intensity of terrestrial laser scanner is not being used for geometric feature extraction of historic buildings. The general aim of this paper is to present a methodology for extracting features of architectural façades. The methodology will use information coming from terrestrial laser scanner and the application of mathematical morphology. Therefore this article is justified in using intensity in the classification, segmentation and feature extraction in current technology.

\section{MATERIALS AND METHODS}

\subsection{STUDY AREA}

The studied façade belongs to Quiñones de León country mansion, which is a typical house of the aristocracy of the north-western region of Galicia in the Iberian Peninsula, built in the seventeenth century (1670), and located in the city of Vigo, Galicia, Spain. In 1924 it was donated to the city by Fernando Quiñones de León, on condition that a museum and a public park are created.

\subsection{RIEGL Z390i EQUIPMENT}

This scanner is based on the time-of-flight (TOF) principle and has a laser source that emits pulses with a wavelength of $1500 \mathrm{~nm}$. This device measures distances in the range of 1.5 to $400 \mathrm{~m}$ with an accuracy rating of 6 $\mathrm{mm}$ at a distance of $50 \mathrm{~m}$ in normal conditions of illumination and reflectivity. The field of vision (FOV) extends to 80 degrees vertically and 360 horizontally. The minimum and maximum angular resolution is $0.2^{\circ}$ and $0.002^{\circ}$, respectively. The measuring point rate is 11,000 points per second. The beam divergence is 0.3 $\mathrm{mrad}$, equivalent to $30 \mathrm{~mm}$ per each $100 \mathrm{~m}$ range. The intensity of the signal received by the sensor system is written in 8 bits [0 255].

\subsection{MATHEMATICAL MORPHOLOGY}

The mathematical morphology [7, 8, 9] refers to nonlinear processing and analysis of geometric structures of images. Morphology is based on the study of decompositions of operators between complete lattices in terms of two classes of elementary operators known as erosion and dilation [10]. The language of mathematical morphology is "set theory", where the sets represent the shapes in an image [11]. The whole theory is based on the use of structural elements, which are well-known and predefined sets. In short, quantifies how the morphology of this element "fits"(or not) in the image.

\subsubsection{Morphological filters}

The two basic operations of morphology are erosion and dilation. The definition of erosion of an image $f$ in grey level by a structuring element $g$ is defined by:

$$
(A \ominus b)(x)=\max \left\{y: g_{x}+y \leq f\right\}
$$

Where $g_{x}$ is the notation for $g$ translated by $x$.

The visual result of the image eroded in grey levels is presented with a reduction of light standards and the extension of the dark regions.

The dilation operator is the "dual" of erosion and is defined by:

$$
(A \ominus b)(x)=\max \left\{y:-g_{x}+y \geq f\right\}
$$


The visual result of the dilated image in grey levels is presented with decreases in dark patterns and enlargement in bright regions. In addition to the primary operations of dilation and erosion, there are two secondary operators in image processing called the opening defined by:

\section{$(A \circ b)(x)=(A \ominus b) \oplus b$}

And its dual, the closing:

$$
(A \bullet b)(x)=(A \oplus b) \Theta b
$$

The result of the implementation of the opening into an image is the removal of lighter areas, while the closing removes dark areas.

\subsection{THE K-MEANS ALGORITHM}

One of the algorithms developed to solve image segmentation problem is the $\mathrm{K}$-means.

The idea of the algorithm is to provide a classification of information according to their own data, based on analyses and comparisons between their numerical values. Thus, the algorithm will provide an automatic sorting without the need of human supervision, that is, without pre-existing classification.

Because of this feature, the K-means is regarded as an unsupervised data mining algorithm.

The unsupervised classification is an automated procedure in which image range is automatically divided into groups according to a statistical procedure, without any predefined knowledge.

In K-means algorithm the user can specify various parameters, including the desired number of clusters and maximum number of iterations allowed in the programme. The main idea is to define $\mathrm{k}$ centroids, one for each class; the next step is to take each pixel belonging to a given data set and associate it with the nearest centroid, and at this point, the centroid should be recalculated. Then we have $\mathrm{k}$ new centroids, and a new connection has to be made between the same set of data points and the new near centroid, these steps defining a new iteration. As this is an iterative process, we can see that the $\mathrm{k}$ centroids change their location step by step until no further change is possible. This algorithm aims to minimize the following function:

$$
I=\sum_{j=1}^{k} \sum_{i=1}^{n}\left\|x_{i}^{(j)}-c_{j}\right\|^{2}
$$

Where, $\left\|x_{i}^{(j)}-c_{j}\right\|^{2}$ is the measurement chosen of distance between a point $x_{i}^{j}$ and in the centre of class $\mathrm{c}_{\mathrm{j}}$, and this is an indicator of the distances between $\mathrm{n}$ points and their respective centres of the classes.

\subsection{DATA ACQUISITION}

The terrestrial laser scanner used was RIEGL LMSZ390i which conducted the survey on the façade of the Quiñones de León country mansion, which has an area of approximately 30 metres long and 15 metres high. Obtained point clouds are composed of 3D points, given in Cartesian coordinates, along with intensity information. The laser survey was carried out at a distance of 41 meters from the façade, to contain the whole façade in a single point cloud and thus, eliminating the need for more than one location (station). The density of points was 1 inch spacing which gave us a cloud of 5,888,344 points. Below, figures 1 and 2 show the Quiñones de León country mansion and the point cloud with intensity value gained by laser scanner.

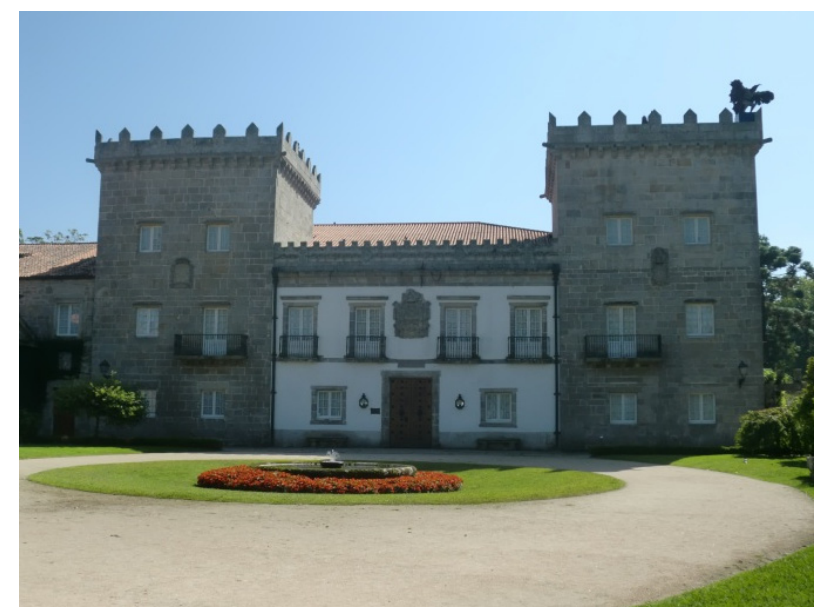

Fig. 1 Quiñones de León country mansion. 


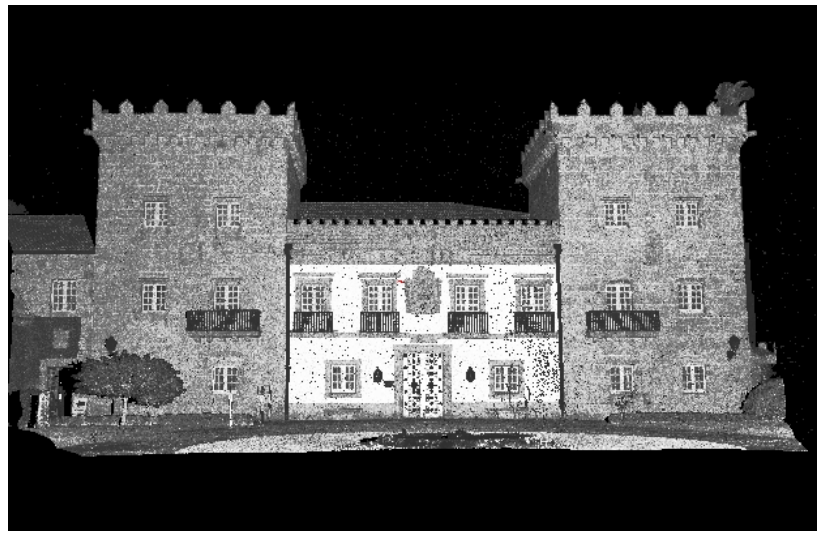

Fig. 2 Point cloud of Quiñones de León country mansion acquired by TLS.

\section{RESULTS AND DISCUSSION}

Once the point clouds were acquired by laser scanner, the first procedure to be carried out is cleaning, where all unwanted points, such us vegetation or elements not belonging to the façade, such as soil, have been removed. This is considered as a first filtering operation.

Figure 3 illustrates the end result of cleaning performed manually on the point cloud obtained by laser.

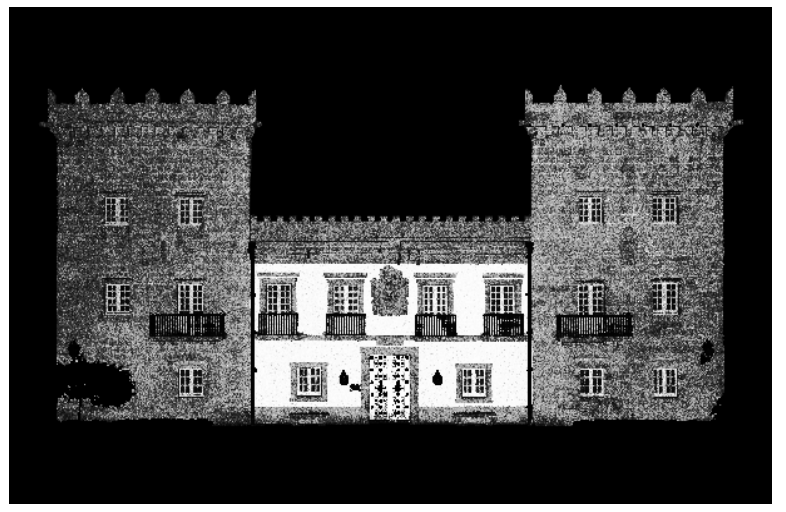

Fig. 3 Result of manual cleaning of point cloud.

Once you get the clean image, the next step is the automatic and unsupervised image classification; this classification was performed using the K-means algorithm which allows you to choose the number of classes; in this case, there were three classes, namely, granite, white wall and iron becausethey are the features that best distinguish the façade. The result of this classification is illustrated in figure 4 , which presents the façade after the cloud unsupervised classification where the different materials found can be seen, granite in blue, the white wall in red and the iron in yellow.

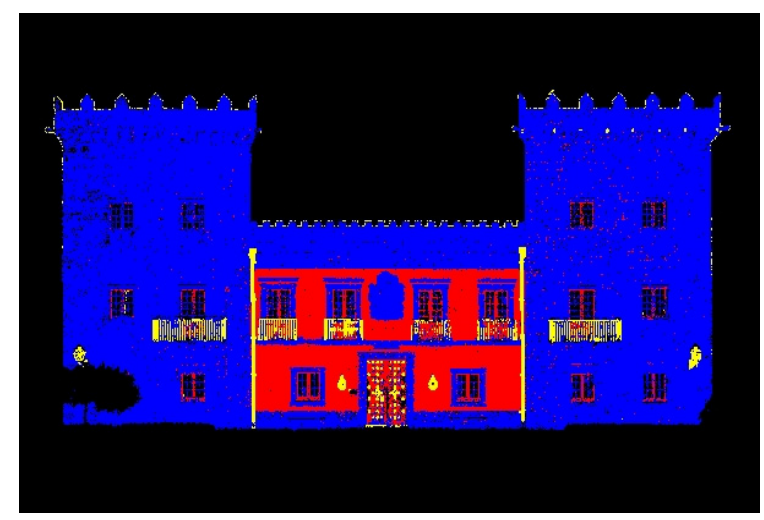

Fig. 4 Façade classified with K-means algorithm (granite in blue, white wall in red and iron in yellow).

A further step after classification was the generation of three images, one for each of their classes (granite, white wall and iron). Each of these images was treated separately in order to draw the contours on each one. For the contour extraction of interesting features, a program was developed within the MATLAB (Matrix Laboratory) environment using mathematical morphology operators contained in the "toolbox".

Below, three images can be observed individually, granite is shown in figure 5, white wall found in figure 6 and iron can be seen in figure 7 .

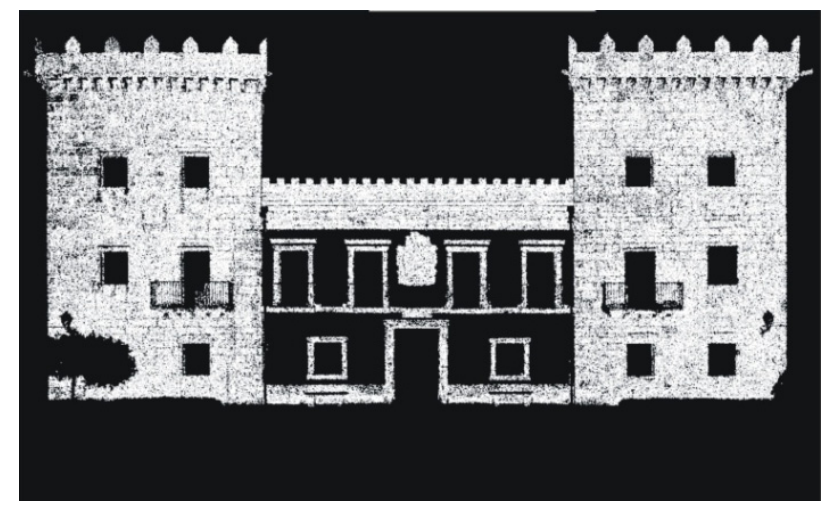

Fig. 5 Façade classified with K-means algorithm and isolated as granite feature. 


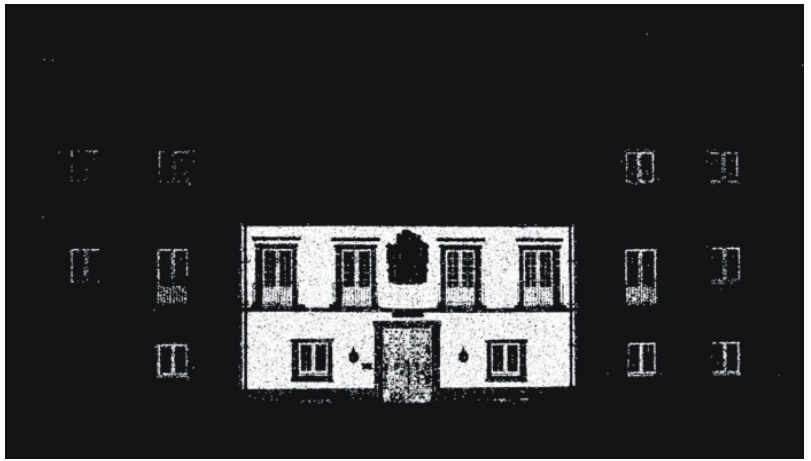

Fig. 6 Façade classified with K-means algorithm and isolated as white wall feature.

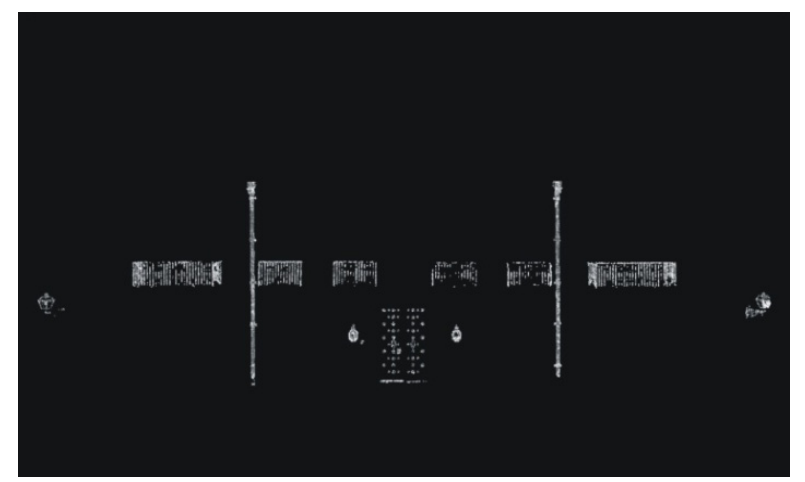

Fig. 7 Façade classified with K-means algorithm and isolated as feature iron.

The operators, "closing" and "opening ", if they are applied together, allow the formation of more compact regions, thus eliminating those too small and thin. The results depend on structural elements, which are the responsible matrix for adding or removing objects in images; the effects depend on the shape or size, which are typically defined by the user depending on the application. According to $\mathrm{Pu}$ et al.[12], mathematical morphology is used to extract components in images which in turn, are useful in the representation and consequently in the description of region shapes, such as borders and skeletons. More information about the mathematical morphology and its operators can also be found in Serra [13].

The end result of the methodology used to extract the façade features is shown in figure 8. It shows the outer contour of the façade with window frames and the door, which were successfully extracted using the classified image with only the feature granite.

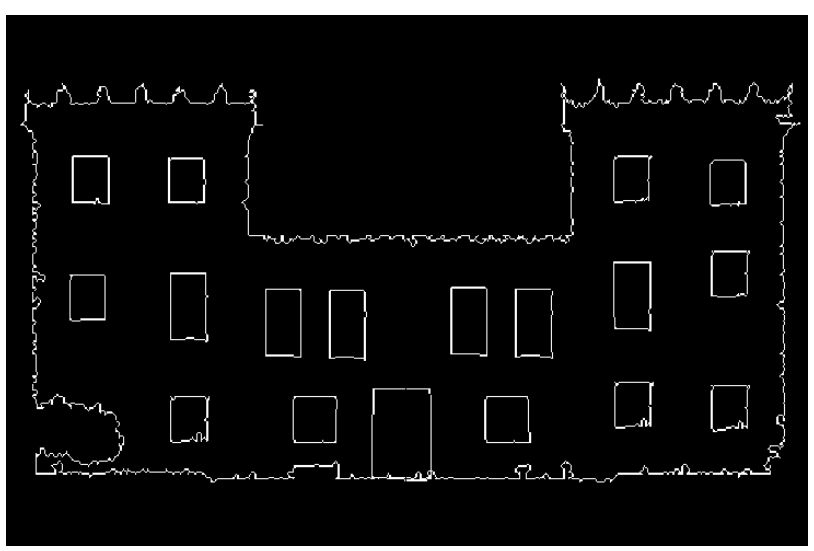

Fig. 8 Façade outer contours, with window frames and the door of Quiñones de León country mansion.

\section{CONCLUSIONS}

This work shows the initial phase to establish a methodology to detect and therefore, to extract features of historic buildings. This methodology uses the intensity value obtained by terrestrial laser scanner, along with the unsupervised classification and mathematical morphology concepts. The proposed methodology has been tested to obtain satisfactory results using the intensity value as a parameter for classification and segmentation of façade features, thus allowing the extraction of characteristics that make up the façades of historic buildings.

The possibility of having extra data (intensity value) may contribute to the detection and extraction of features of historic buildings, in addition to the geometric information of data provided by TLS systems.

In this way, the end result shows that from the intensity data, it is possible to extract the main features of façades with the appropriate use of mathematical morphology operators, once the image has been segmented using the K-means algorithm. In fact, it could be said that both, images from laser and mathematical morphology operators are viable tools for feature extraction processes for the documentation of historical heritage. 


\section{ACKNOWLEDGMENTS}

The authors want to thank CAPES Foundation Ministry of Education of Brazil (Process code 0064-10-6), the Ministry of Science and Innovation of Spain (Project code BIA2009-08012) and Regional Ministry of Economy and Industry-Xunta de Galicia (Isabel Barreto EXP114) for the financial support.

\section{REFERENCES}

[1] $\mathrm{Pu} \mathrm{S,} \mathrm{Vosselman} \mathrm{G.,} \mathrm{"Knowledge} \mathrm{based}$ reconstruction of building models from terrestrial laser scanning data", ISPRS Journal of Photogrammetry and Remote Sensing, Vol. 64, Issue 6, pp.575-584, 2009.

[2] Buckley, S.J., Howell, J.A., Enge, H.D., Kurz, T.H., "Terrestrial laser scanning in geology: data acquisition, processing and accuracy considerations", Journal of the Geological Society, Vol. 165, pp. 625-638, 2008.

[3] Guidi, G., Remondino, F., Russo, M., Menna, F., Rizzi, A., Ercoli, S., "A multi-resolution methodology for the 3D modeling of large and complex archeological areas", International Archives of Photogrammetry, Remote Sensing and Spatial Information Sciences, 2008.

[4] Hori, Y., Ajioka, O., Hanghai, A., "Laser Scanning in Pompeian City wall - A comparative study of accuracy of the drawings from 1930s to 1940s", International Archives of Photogrammetry, Remote Sensing and Spatial Information Sciences, 36(5/W7), 2007.

[5] Armesto, J., Ordóñez, C., Alejano, L., Arias, P., "Terrestrial laser scanning used to determine the geometry of a granite boulder for stability analysis purposes", Geomorphology, Vol. 106, pp. 271-277,2009.

[6] González-Aguilera, D., Gómez-Lahoz, J., Sánchez, J. "A new approach for structural monitoring of large dams with a three-dimensional laser scanner", Sensors, Vol.8, pp. 5866-5883, 2008.

[7] Matheron, M., "Random Sets and Integral Geometry", Wiley, New York, 1975.

[8] Serra, J., "Image Analysis and Mathematical Morphology”, Orlando, FL, USA: Academic Press, Inc., 1983.
[9] Sternberg, S.R., "Grayscale morphology", Comput. Vision Graph. Image Process., Vol. 35, n. 3, pp. 333-355, 1986.

[10] Banon, G.J.F., Barrera, J., "Set operator decomposition and conditionally translation invariant elementary operators". Proceedings of the ISMM'94, Fontainebleau, 1994.

[11] Haralick, R.M., Sternberg, S.R., Zhuang, X., "Image analysis using mathematical morphology", IEEE Trans. Pattern Anal. Mach. Intell., IEEE Computer Society, Washington, DC, USA, v. 9, n. 4, pp. 532-550, 1987.

[12] Gonzales, R. C, Woods, R., "Processamento de imagensdigitais”. São Paulo: EdgardBlücher, 508p., 2000. [13] Facon, J., "Morfologia Matemática: Teorias e Exemplos", Editora UniversitáriaChampagnat da PontifíciaUniversidade Católica do Paraná, Curitiba, 320p., 1996. 